\title{
Internet das Coisas: Utilização do Arduino para o combate ao desperdício elétrico no IFMA Campus São João dos Patos
}

\author{
Internet oh Things: Use of Arduino to combat electric waste in IFMA Campus São João dos Patos \\ Internet de las Cosas: Uso de Arduino para combatir los resíduos eléctricos em IFMA Campus São \\ João dos Patos
}

Recebido: 19/06/2020 | Revisado: 23/06/2020 | Aceito: 26/02/2021 | Publicado: 03/03/2021

\author{
Antonio Marques dos Santos \\ ORCID: https://orcid.org/0000-0003-2822-0710 \\ Instituto Federal de Educação, Ciência e Tecnologia do Rio Grande do Norte, Brasil \\ E-mail: antonio.marques@ifrn.edu.br \\ Gautama Silva dos Santos \\ ORCID: https://orcid.org/0000-0003-2688-9373 \\ Professor da Prefeitura Municipal de São João dos Patos, Brasil \\ E-mail: gautamass@yahoo.com.br \\ Abílio Soares Coelho \\ ORCID: https://orcid.org/0000-0003-2822-0710 \\ Instituto Federal de Educação, Ciência e Tecnologia do Maranhão, Brasil \\ E-mail: abílio.coelho@ifma.edu.br
}

\begin{abstract}
Resumo
As despesas com energia elétrica em 2015 comprometeram 11,83\% do orçamento, o equivalente a R 201758,40 do orçamento do IFMA São João dos Patos que foi da ordem de R\$ 2611 847,51. Fazer o monitoramento eficiente destes custos pode resultar em uma economia significativa no consumo de energia elétrica e na contenção de gastos. O ponto de partida para o desenvolvimento do projeto foi o auto custo das contas de energia elétrica no campus, ocasionado pelo desperdício enérgico, tendo como principal fator o uso inadequado dos aparelhos de ar condicionado, pois verificou-se que estes permanecem ligados desnecessariamente contribuindo para o aumento do consumo elétrico e, consequentemente, a elevação no valor da conta de energia. Não há como saber quais unidades estão em uso ou obter informações com relação à temperatura ambiente. Outro fator que contribui para o agravamento desse problema é a permanência de lâmpadas acesas quando não está acontecendo atividade pedagógica naquele ambiente. Isto ocorre devido ao campus dispor de um único servidor para desempenhar a função de ligar/desligar estes aparelhos. O foco deste trabalho é o desenvolvimento e implantação de uma central de automação de baixo custo, a partir da interação entre uma placa Arduino Uno e um shield ethernet controlada remotamente via internet. Para tanto, foi desenvolvido um aplicativo para dispositivos móveis (celular, tablet) que utilizem o sistema operacional Android para controlar todas as funções dos aparelhos de ar condicionado do IFMA de São João dos Patos. O Aplicativo escolhido para desenvolver o App foi o TouchOSC que utiliza o protocolo TCP/IP para receber e enviar informações entre o Arduino e o dispositivo móvel. Outra razão que levou a escolha desse App foi o fato dele apresenta uma interface gráfica amigável e por não exigir conhecimento em programação JAVA para desenvolver o aplicativo. As mensagens serão enviadas através da comunicação wi-fi permitindo o acionamento dos ar condicionados de qualquer lugar do mundo. Para o desenvolvimento do aplicativo foi utilizado as linguagens Processing e $\mathrm{C}++$.
\end{abstract}

Palavra-chave: Microcontrolador; Internet das coisas; Prototipação.

\begin{abstract}
The cost of electricity in 2015 pledged $11.83 \%$ of the budget, equivalent to R \$ 201758.40 of the IFMA São João dos Patos budget was R \$ 847.51 Order 2611. Make efficient monitoring of these costs can result in significant savings in power consumption and cost containment. The starting point for the development of the project was the self cost of electricity bills on campus, caused by energetic waste, the main factor inappropriate use of air conditioners as these that there remain on unnecessarily contributing to increasing the power consumption and, consequently, the increase in power account value. There is no way to know which units are in use or information with respect to room temperature. Another factor that contributes to the worsening of this problem is the length of lighted lamps when not going pedagogical activity in that environment. This is due to the campus to have a single server to perform the function on / off these devices. The focus of this work is the development and implementation of a low-cost automation center, from the interaction between an Arduino Uno board and an ethernet shield controlled remotely via the Internet. Therefore, an application was developed for mobile devices (mobile, tablet) that use the Android operating system to control all functions of the air conditioners of São João dos Patos IFMA. The application chosen
\end{abstract}


to develop the App was TouchOSC that uses the TCP / IP protocol to send and receive information between the Arduino and the mobile device. Another reason for the choice of this App was the fact that it features a friendly graphical user interface and does not require knowledge of Java programming to develop the application. Messages will be sent via wi-fi allowing the activation of conditioned air from anywhere in the world communication. For application development was used the Processing and $\mathrm{C}++$ languages.

Keyword: Microcontroller; Internet of things; Prototyping.

\section{Resumen}

Los gastos de electricidad en 2015 comprometieron el 11,83\% del presupuesto, equivalente a R \$201 758,40 del presupuesto de IFMA São João dos Patos, que fue del orden de R \$ 2.611.847,51. El monitoreo eficiente de estos costos puede resultar en ahorros significativos en el consumo de electricidad y ahorros de costos. El punto de partida para el desarrollo del proyecto fue el costo del auto de las facturas de luz en el campus, causado por el desperdicio energético, teniendo como factor principal el uso inadecuado de los dispositivos de aire acondicionado, ya que se encontró que permanecen conectados contribuyendo innecesariamente a la aumento del consumo eléctrico y, en consecuencia, aumento del valor de la factura energética. No hay forma de saber qué unidades están en uso ni de obtener información sobre la temperatura ambiente. Otro factor que contribuye al agravamiento de este problema es la permanencia de las lámparas encendidas cuando no hay actividad docente en ese entorno. Esto se debe a que el campus cuenta con un único servidor para realizar la función de encender / apagar estos dispositivos. El enfoque de este trabajo es el desarrollo e implementación de un centro de automatización de bajo costo, basado en la interacción entre una placa Arduino Uno y un escudo ethernet controlado remotamente a través de Internet. Para ello, se desarrolló una aplicación para dispositivos móviles (teléfono celular, tableta) que utilizan el sistema operativo Android para controlar todas las funciones de las unidades de aire acondicionado de IFMA en São João dos Patos. La aplicación elegida para desarrollar la aplicación fue TouchOSC que usa el protocolo TCP / IP para recibir y enviar información entre el Arduino y el dispositivo móvil. Otro motivo que llevó a la elección de esta App fue el hecho de que cuenta con una interfaz gráfica amigable y no requiere conocimientos en programación JAVA para desarrollar la aplicación. Los mensajes se enviarán mediante comunicación wi-fi permitiendo la activación de aires acondicionados desde cualquier parte del mundo. Para el desarrollo de la aplicación se utilizaron los lenguajes Processing y C ++.

Palabra clave: Microcontrolador; Internet de las cosas; Prototipos.

\section{Introdução}

O projeto apresenta o funcionamento de uma central de automação que possibilita a comunicação entre uma placa ATmega com um Ethernet Shield e um celular IOS para controlar todas as funções do ar condicionado através de um aplicativo que utiliza o protocolo OSC.

De acordo com Sgarbi e Tonidandel (2006), a palavra domótica surgiu da fusão entre a palavra latina domus (casa) e robótica (integração de diversas tecnologias no ambiente doméstico).

A domótica vem crescendo exponencialmente nos últimos anos, o que lhe proporcionou um lugar de destaque no mercado mundial. Com isso, novas tecnologias surgiram trazendo maior conforto e comodidade às pessoas. Além disso, sua utilização possibilita a redução no consumo de energia elétrica.

O sistema proposto foi desenvolvido a partir do estudo de vários protocolos de comunicação onde ao final optou-se pelo uso do wi-fi, TCP e OSC. A escolha desses protocolos se deu pela presença maciça na maioria dos dispositivos móveis e por ser uma das principais formas de conexão com a internet respectivamente.

Os componentes que integram a central de comando são: um emissor e receptor infravermelho, um resistor de 330 Ohm, um Arduino Uno, um shield ethernet e um celular. Para a aplicação do projeto foi desenvolvido um aplicativo para o sistema operacional IOS que gerenciasse o uso dos aparelhos de ar condicionado do IFMA/São João dos Patos. Os comandos serão enviados ao roteador via wireless para serem processados na plataforma Arduino que irá ativar/desativar os sensores e atuadores interligados a ele.

Em 1999 Kevin Ashton, um dos co-fundadores do Auto-ID Center do Massachusetts Institute of Technology (MIT), usou pela primeira vez o termo Internet das Coisas (IoT) durante uma apresentação na empresa Procter \& Gamble (P\&G). 
Segundo Correia (2010), o conceito de Internet das Coisas está associado à ideia de que todos os objetos podem ser interligados via internet. Para isso, basta haver um dispositivo de comunicação e localização (RFID) para trocar informações entre si e tomar decisões a partir das informações obtidas.

A "Internet das Coisas" se refere a uma revolução tecnológica que em breve conectará equipamentos como eletrodomésticos, meios de transporte, roupas e maçanetas conectadas à Internet e a outros dispositivos, como computadores e smartphones (Zambarda, et. al, 2014).

Um dos grandes diferenciais da Internet das Coisas está relacionado à possibilidade de tornar possível o monitoramento das coisas por meio de sensores e microchips sem a intervenção humana. Esse novo conceito de internet permite a interação M2M (máquina-a-máquina) permitindo o cruzamento de dados para atender a necessidades do dia-a-dia.

Acredita-se que a IoT tenha surgido entre os anos de 2008 e 2009, como mostra a Figura 1:

Figura 1: Surgimento da internet das coisas.

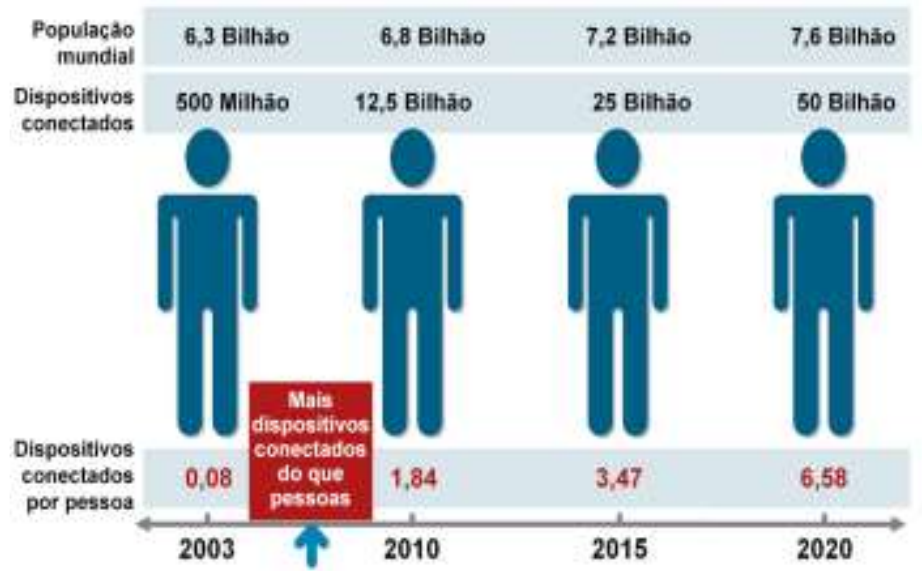

Fonte: Cisco IBSG (Abril de 2015).

A cada instante a tecnologia vem promovendo transformações nos hábitos sociais das pessoas. A interatividade da internet com outras tecnologias e equipamentos vem mudando a rotina do cidadão comum e dos grandes empresários, seja em seus lares ou no seu local de trabalho. Nesse exato momento há bilhões de dispositivos gerando e processando informações sobre temperaturas, velocidades, consumo de energia.

Segundo a Cisco em 2020 haverá cinquenta bilhões de dispositivos ligados à Internet, ou seja, mais do dobro dos habitantes do planeta. Isto significará que a Internet deixará de ser uma rede para interligar pessoas e passará a ser uma rede de coisas.

Para desenvolver o aplicativo (App) foi utilizado o TouchOSC que utiliza o protocolo TCP/IP para receber e enviar informações entre o Arduino e o dispositivo móvel. Outra razão que levou a escolha desse App foi o fato de ele apresentar uma interface gráfica amigável e por não exigir conhecimento em programação JAVA para desenvolvê-lo. As mensagens serão enviadas através da comunicação wi-fi permitindo o acionamento dos ares condicionados a grandes distâncias pelo usuário desde que esteja conectado na mesma rede. Para o desenvolvimento do aplicativo foi utilizado as linguagens Processing e $\mathrm{C}++$.

\section{Metodologia}

Para a concretização deste trabalho foi necessário a realização de estudos aprofundados sobre os componentes físicos e lógicos que compõem o protótipo e das tecnologias utilizadas no desenvolvimento do aplicativo que irá controlar os ares 
condicionados. A fundamentação teórica teve como base artigos científicos, trabalhos de conclusão de curso, livros e materiais publicados na internet. Para coleta de dados foi utilizado relatórios, documentos, observações e implantação do sistema para verificar a sua eficácia no controle da redução do consumo de energia no campus.

Para a criação do protótipo foi utilizado um conjunto de softwares/hardwares que atendem aos requisitos de execução dos comandos de acordo com as especificações do programa. Apresentou-se também conceitos acerca das tecnologias utilizadas no protótipo.

O protótipo foi construído a partir de 2 placas Arduino Uno, 1 Shield Ethernet W5100, 1 LED emissor e 1 receptor infravermelho, 1 resistor de 330 Ohms e um celular com sistema operacional IOS.

\subsection{Tecnologias aplicadas}

Os softwares e hardwares utilizados neste trabalho foram essenciais para a materialização do protótipo, porém, é importante mencionar que é a tecnologia de comunicação sem fio "wi-fi" a responsável pelo envio e recepção das informações necessárias para o funcionamento do sistema.

\subsection{A plataforma arduino uno}

Desenvolvido na Itália, o Arduino consiste em uma plataforma de código aberto destinado a criação de protótipos. (SILVA, 2014). De acordo com McRoberts (2011), o Arduino assume o papel de software/hardware e apresenta uma interface amigável e de fácil uso. O projeto original foi desenvolvido para um público bastante eclético abrangendo estudantes, artistas, designers e pessoas que demonstrasse interesse pelo assunto.

A Figura 2, apresenta a Placa Arduino Uno utilizada neste projeto e que serviu de subsidio para a implantação do sistema.

Figura 2: Placa Arduino.

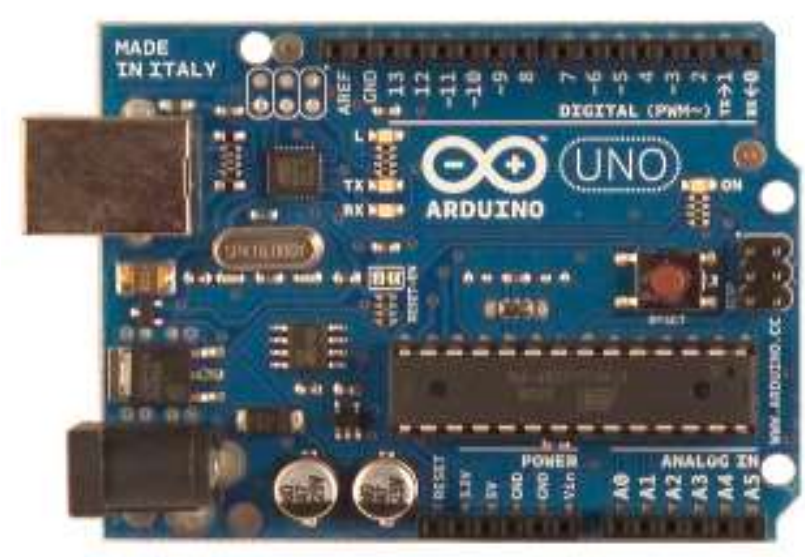

Fonte: https://www.arduino.cc/

Seu uso pode ser feito a partir da interação entre um computador e alguns aplicativos como o Adobe Flash, Processing, Max/MSP, Pure Data ou Super Colider. Por se tratar de uma multiplataforma sua configuração pode ser feita em vários ambientes Mac OS, Linux e Windows. 
A linguagem de programação é baseada em wiring, o ambiente de desenvolvimento (Integrated Development Environment - IDE) tem origem em processing o que a torna de fácil entendimento graças as bibliotecas que possibilitam a criação de funções através de uma sintaxe parecida com a linguagem $\mathrm{C} / \mathrm{C}++$.

\subsection{0 shield ethernet w5100}

A popularidade do Arduino no mundo acadêmico está relacionada à sua grande versatilidade. Isto só é possível devido ao uso de Shields integradas à ele. As Shields são placas de circuito compostas por sensores, displays de LCD, módulos de comunicação ou relês que podem ser acopladas às placas Arduino e conectadas à internet através de um (IP) nos protocolos TCP ou UDP e é facilmente utilizado usando a biblioteca Ethernet Library e SD Library (McRoberts). Assim, o seu monitoramento pode ser feito via web a partir de um celular.

\section{Figura 3: Shield Ethernet.}

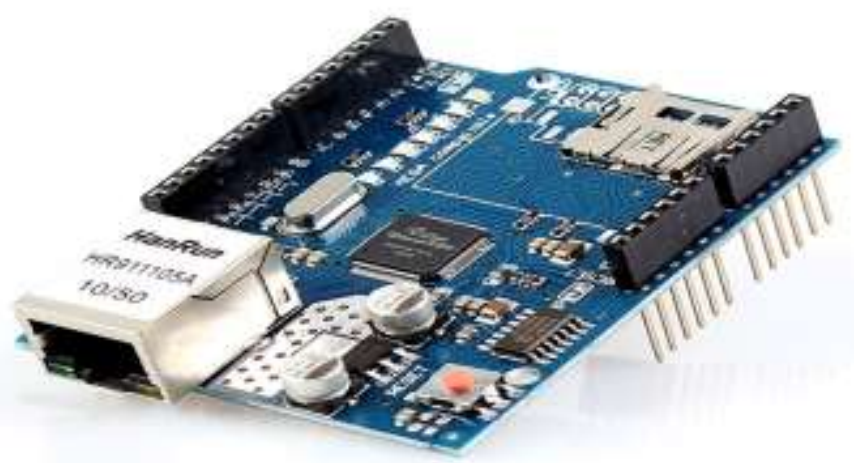

Fonte: https://www.arduino.cc/

A comunicação entre o Arduino e o Shield Ethernet é feita através de um cabo de rede tornando possível o monitoramento dos aparelhos de ar condicionado a partir da rede local ou de qualquer lugar desde que haja uma rede disponível.

A interação Ethernet Shield e Arduino com a internet será feita por meio de um cabo ethernet e suporte à rede TCP e UDP. Suportando até quatro conexões de soquetes e com uma velocidade de conexão de 10/100 MB. 
Figura 4: Arduino acoplado a um shield conectado ao cabo ethernet.

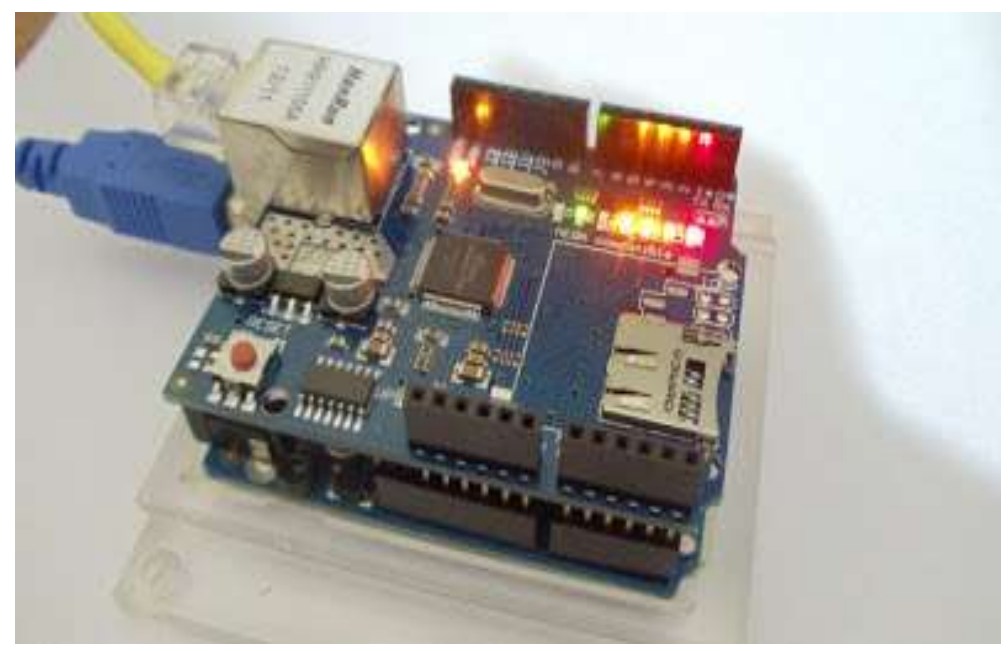

Fonte: http://www.arduinoecia.com.br/

\subsection{Sensores infravermemelhos}

Os sensores são dispositivos que respondem a um estímulo físico/químico de maneira específica e mensurável analogicamente.

De acordo com a Cisco, a presença de sensores nas indústrias, prédios e residências é muito forte em decorrência do grande número de dispositivos integrados e controlados remotamente, pois a automação se transformou em uma alternativa na redução do consumo de energia elétrica.

Os sensores infravermelhos ocupam uma posição de destaque quando o assunto é automação, pois possuem uma infinidade de aplicações que vão desde o código de barras até as chaves ópticas e detectores.

Os sensores infravermelhos são classificados com base em suas propriedades funcionais. Neste trabalho foi utilizado sensores infravermelho, um LED e uma placa Arduino.

Figura 5: LED e Receptor Infravermelho.

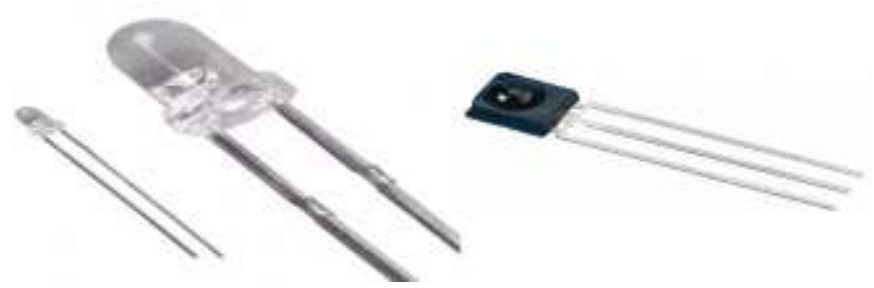

Fonte: http://www.arduinoecia.com.br/

\subsection{Protocolos OSC}

A interface do aplicativo a ser instalado no celular pode ser alterado facilmente através da ferramenta TouchOSC, onde o usuário pode criar telas de acordo com as especificações do projeto. Outra vantagem desse aplicativo está associada ao fato dele possuir a biblioteca ARDOSC compatível com a placa Arduino, tornando a comunicação entre ambos mais eficiente. $\mathrm{O}$ aplicativo apresenta respostas rápidas aos comandos recebidos. O download está disponível na página do fabricante http://hexler.net/software/touchosc.

A comunicação entre o Arduino e o dispositivo móvel será feita por meio do TouchOSC utilizando um protocolo TCP/IP para transmissão e recepção das informações por meio de uma rede wi-fi. 
Research, Society and Development, v. 10, n. 3, e231035794, 2021

(CC BY 4.0) | ISSN 2525-3409 | DOI: http://dx.doi.org/10.33448/rsd-v10i3.5794

Figura 6: Ambiente de personalização do TouchOSC.

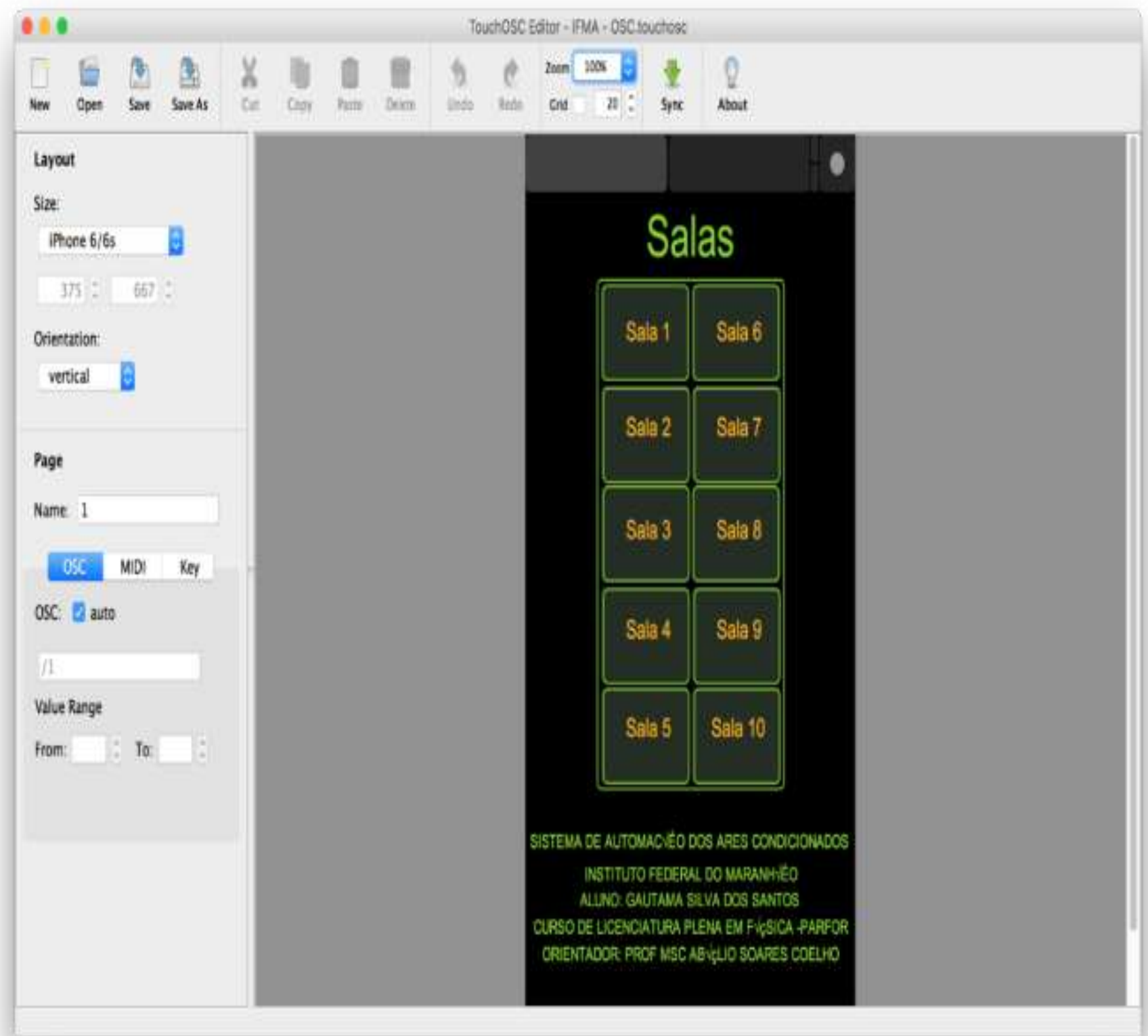

Fonte: Autores.

Através da ferramenta TouchOSC Editor pode-se personalizar a interface gráfica colocando legendas para facilitar o entendimento do usuário final, clicando com o botão direito e selecionando (label VII). 
Figura 7: Adicionando funções ao aplicativo.

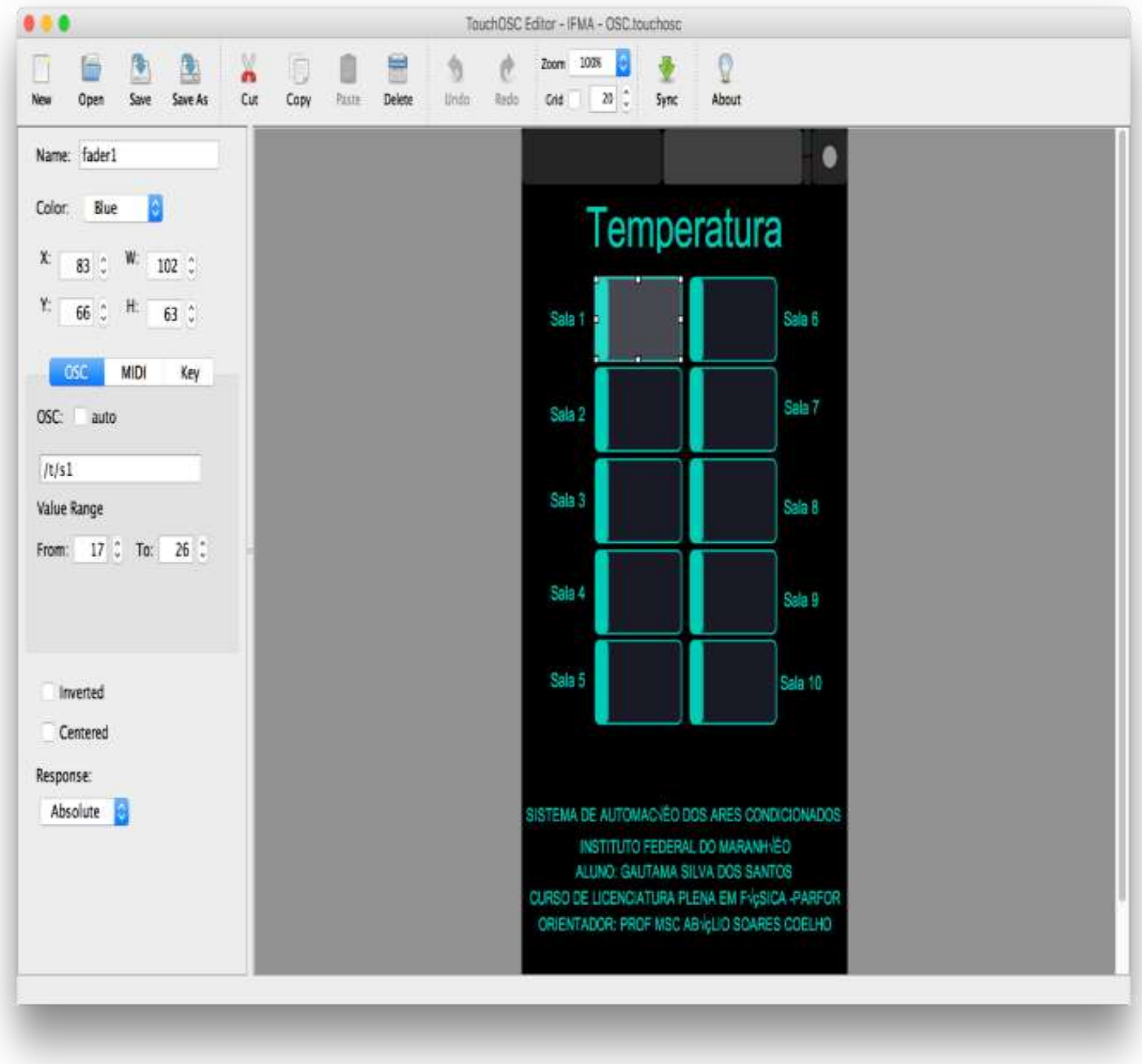

Fonte: Autores.

\subsection{Central de automação}

O foco deste trabalho está voltado para a automação dos aparelhos de ar condicionado do IFMA/São João dos Patos. Tem-se como objetivo a implementação de uma central de automação que otimize o gerenciamento do consumo energético e que possua um custo de implantação acessível.

Essa necessidade é resultante de um trabalho que esta sendo desenvolvido pelo Campus do IFMA de São João dos Patos que através da comissão de sustentabilidade está buscando ações que visem o gerenciamento de energia no campus, já que este funciona com o uso de ar condicionada nos departamentos, salas de aula e laboratório nos três turnos.

A figura 8 ajuda a melhor compreender o funcionamento do sistema proposto neste trabalho. O dispositivo móvel envia os comandos para o Arduino que os processa e transforma em informações que são enviados para o ar condicionado. 
Figura 8: Diagrama da central de automação desenvolvida.

$\begin{array}{cc}\text { Dispositivo Móvel } & \text { Roteador } \\ & \text { ao Arduino }\end{array}$
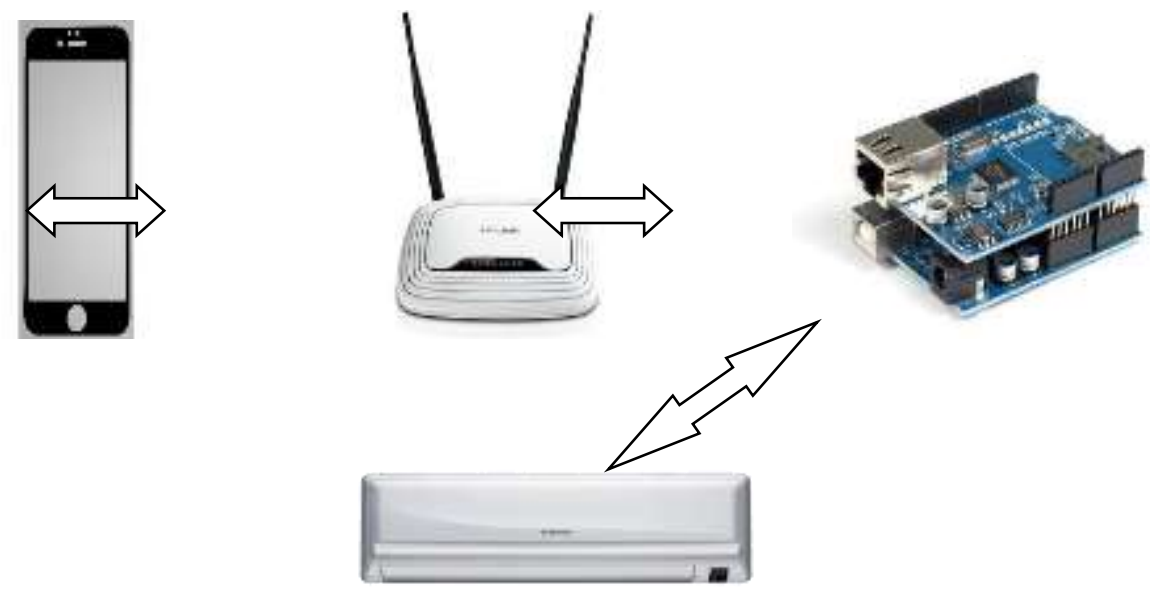

Ar condicionado

Fonte: Autores.

A central é formada por uma placa Arduino, um shield ethernet que faz a comunicação com o mundo externo via internet por meio de um celular.

\section{Considerações Finais}

O Campus do IFMA de São João dos Patos desde a sua inauguração está diante de um grande desafio, reduzir o consumo de energia elétrica. A falta de controle sobre os aparelhos de ar condicionados é o principal fator que contribui para o desperdício de energia elétrica, pois, muitas vezes, as unidades ficam ligadas desnecessariamente. O cenário atual, não permite saber em quais salas estão sendo ministradas aulas naquele momento, obter informações sobre a temperatura destas e quais unidades estão ligadas. Isto ocorre devido ao campus dispor de um único servidor para desempenhar a função de ligar/desligar estes aparelhos, o que torna o controle do consumo elétrico mais difícil. Outro fator que encarece a conta de energia está relacionado ao modelo de ar condicionado instalado no campus, isto é, todos os aparelhos estão inseridos na classe $\mathrm{E}$ de consumo do Instituto de Metrologia (Imetro) e com potência de 60 000btus (British Thermal Unit). A combinação destes fatores gera um aumento no consumo de energia o que poderia ser evitado, caso pudesse receber ou enviar informações de forma centralizada a esses aparelhos.

Os dados analisados foram fornecidos pelo setor contábil do campus e são referentes ao consumo de energia elétrica entre os meses de janeiro a dezembro de 2015. De acordo com a análise destes constatou-se que o gasto com energia chega a comprometer 11,83\% do orçamento financeiro do campus, que foi de $\mathrm{R} \$ 2$ 611 847,51 no referido ano, gerando um aumento significativo nas despesas com energia elétrica, no final do mês.

Percebemos que o consumo de energia elétrica do campus aumenta acentuadamente nos meses compreendidos entre janeiro e junho e decai durante o mês de julho, período em que os alunos estão de férias. No segundo semestre, como já era esperado, o consumo de energia volta a aumentar devido ao clima da região que exige um maior funcionamento dos aparelhos de ar condicionados. 
Com a implantação deste projeto espera-se que o desperdício de energia seja resolvido, pois o acionamento dos aparelhos de ar condicionado será totalmente automatizado através da central de controle via celular.

A partir da utilização do Arduino Uno como central de automação verificou-se sua versatilidade para o controle de aparelhos elétricos. Além de ser uma ferramenta de fácil implementação, apresenta algumas limitações em sua estrutura, como capacidade de portas de saída e de processamento de informações. A escolha do protocolo TouchOSC para a criação do aplicativo se deu ao fato de não exigir conhecimento aprofundado em programação JAVA por parte dos usuários que utilizam o sistema operacional IOS existente na maioria dos celulares.

O sistema apresentado neste trabalho permite ao usuário aperfeiçoar e ampliar suas funções, tendo em vista que a automação apresenta um vasto leque de possibilidades além da apresentada nesse projeto como, por exemplo, a utilização de sensores de luminosidade para ligar e desligar as lâmpadas de todas as dependências do prédio.

Em linhas gerais conclui-se que o trabalho desenvolvido conseguiu atingir seus objetivos, uma vez que o aplicativo produzido foi capaz de monitorar remotamente $\mathrm{o}$ acionamento dos ares condicionados, permitindo assim um acompanhamento mais efetivo sobre o uso destes aparelhos e evitando o desperdício de energia elétrica, o que consequentemente reduzirá as despesas com energia elétrica no Campus.

\section{Referências}

Arduino -http://playground.arduino.cc//Portugues/HomePage.

A Interne Das coisas - Como a próxima evolução da Internet está mudando tudo. www.cisco.com/web/BR/assets/executives/.

Cardoso, F. A. S. - Automação Residencial com Integração do Arduino e SO Android: Um Estudo de Caso ${ }^{1}$. https://docs.google.com/file/d/0 B9bS_lg4EeHKYm93bnBUR0ZPX0U/edit?pref=2\&pli=1.

Correia, J.; Silveira, C. V. R. \& Virtudes, J. (2011). Sistemas de Recuperação de Informação. Trabalho da disciplina de Seminário de Sistemas e Tecnologias da Informação I. Universidade Atlântica, Portugal. http://ssti1-1112.wikidot.com/a-internet-das-coisas.

Cruz, M. M. Climaduino: sistema embarcado de climatização para edifícios inteligentes. Trabalho de Conclusão do Curso de Tecnólogo em Redes de Computadores da Universidade Federal do Ceará Campus Quixadá. http://www.repositoriobib.ufc.br/000012/000012fc.pdf.

Cunha, T. F., Controle centralizado de equipamentos de ar condicionado via rede sem fio ZigBee. Monografia apresentada `a Coordenação do Curso Superior de Tecnologia em Sistemas do Instituto Federal de Santa Catarina. em wiki.sj.ifsc.edu.br/wiki/images/1/14/TCC_ThiagoFelipeCunha.pdf.

Esse tal de Arduino - Por Tatiana de Mello Dias - O Estado de S. Paulo. http://link.estadao.com.br/noticias/geral,esse-tal-de-arduino,10000036492.

Maestrelli, L. H. M. Automação residencial via Web. Projeto Final apresentado ao Programa de Aprendizagem de projeto final II, do Curso de Graduação em Engenharia de Computação da Pontifícia Universidade Católica do Paraná. www.ppgia.pucpr.br/ laplima/ensino/pfec/concluidos/2010/autores.pdf.

Maia, G. M. F., Acionamento remoto de portões elétricos via celular através de microcontrolador. Trabalho de Conclusão de Curso de Engenharia de Computação do Centro Universitário de Brasília - http://www.repositorio.uniceub.br/bitstream/123456789/3104/3/20855679.pdf.

Mcroberts, M., Arduino Básico / Michael McRoberts; [tradução Rafael Zanolli]. -Novatec Editora, 2011.

Neto, R. O. Automação de iluminação residencial utilizando microcontrolador arduino e tablet ipad via wi-fi. Trabalho de Conclusão de Curso de Engenharia de Computação do Centro Universitário de Brasília - UniCEUB. www.repositorio.uniceub.br/bitstream/123456789/3197/2/20615176.pdf.

Pessoa, C. R. M. A internet das coisas: será a internet do futuro ou está prestes a se tornar a realidade do presente? www.fumec.br/revi stas/eol/article/download/2961/1732. 